\title{
Recurrent Malignant Hemangiopericytoma
}

National Cancer Institute

\section{Source}

National Cancer Institute. Recurrent Malignant Hemangiopericytoma. NCI Thesaurus. Code C9254.

A rare malignant mesenchymal neoplasm, believed to have its orig in in smooth muscle derived pericytes, which has recurred after treatment. 